\title{
PRIVATIZAÇÃO DA EDUCAÇÃO EM 24 PAÍSES AFRICANOS: TENDÊNCIAS, PONTOS COMUNS E ATÍPICOS
}

\author{
RUI DA SILVA ${ }^{1}$ \\ JOANA Oliveira ${ }^{2,3}$
}

\begin{abstract}
RESUMO: O artigo busca focar nas principais tendências no âmbito da privatização da educação em 24 países africanos considerados frágeis pela Parceria Global para a Educação, comparando as diferenças e os pontos em comum. Com esse objetivo, recorre-se a um corpus documental para a realização de análise de conteúdo dos dados invocados, de modo a evidenciar o conteúdo manifesto. A análise realizada permite inferir que predomina, nos diferentes países, a perspectiva da privatização da educação planejada em detrimento da de facto, e constatar que, quando os documentos mencionam a gestão privada, referem-se, principalmente, à comunidade/aos pais. Concluiu-se que predomina a perspectiva de que as decisões são baseadas em evidências científicas, existindo, contudo, cinco países considerados atípicos.
\end{abstract}

Palavras-chave: Privatização da educação. Sul Global. África. Parceria Global para a Educação.

\section{PRIVATIZATION OF EDUCATION IN 24 AFRICAN STATES: TRENDS, COMMON POINTS, AND OUTLIERS}

\begin{abstract}
The article aims to focus on the main trends related to the privatization of the education in 24 African countries considered fragile by the Global Partnership for Education, comparing differences and common points. To achieve this goal, a documental corpus was used for the content analysis of the gathered data, as to emphasize the expressed content. The analysis shows the predominance, in the different countries, of the perspective of planned privatization of education, not de facto. It also allowed us to conclude that, when the documents mention private management, they refer to the community/the parents. It was also concluded that there is a predominance of decisions based on scientific evidences, although five countries can be considered outliers.
\end{abstract}

Keywords: Privatization of education. Global South. Africa. Global Partnership for Education.

\footnotetext{
*O presente artigo está vinculado à pesquisa financiada pela Fundação para Ciência e Tecnologia com a referência CEECIND01263/2017.

1.Universidade do Porto - Centro de Estudos Africanos da Universidade do Porto - Porto, Portugal. Email: rdasilva.email@gmail.com 2.Escola Superior de Educacao - Instituto Politecnico de Viana do Castelo - Viana do Castelo, Portugal. Email: joanaoliveira@ese.ipvc.pt 3.Universidade do Porto - Centro de Estudos Africanos da Universidade do Porto - Porto, Portugal
} 


\title{
PRIVATIZACIÓN DE LA EDUCACIÓN EN 24 PAÍSES AFRICANOS: TENDENCIAS, PUNTOS COMUNES Y ATÍPICOS
}

\begin{abstract}
RESUMEN: El artículo busca enfocarse en las principales tendencias en el alcance de la privatización de la educación en 24 países africanos considerados frágiles por la Alianza Global para la Educación, comparando las diferencias y los puntos comunes. Para este fin, se utiliza un corpus documental para llevar a cabo el análisis de contenido. El análisis permitió inferir que la privatización de la educación planificada predomina en los países en detrimento de la privatización de facto, y considerar que, cuando los documentos mencionan gestión privada, se refieren a la comunidad/los padres. El análisis también permitió verificar que prevalece la perspectiva de que las decisiones se basan en evidencia científica. Sin embargo, hay cinco países considerados atípicos.
\end{abstract}

Palabras-clave: Privatización de la educación. Sur Global. África. Alianza Global para la Educación.

\section{Introdução}

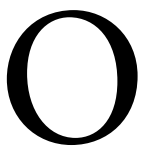

presente artigo pretende analisar e refletir sobre as principais tendências no âmbito da privatização da educação, verificadas em 24 países africanos considerados frágeis e afetados por conflito pela Parceria Global para a Educação (PGE) e que contam com o apoio financeiro desse fundo, comparando suas diferenças e seus pontos comuns.

Partimos do pressuposto de que a educação é um bem público (LEVIN, 2001; LUBIENSKI, 2009; RIZVI, 2016) e um direito humano (MCCOWAN, 2013) fundamental para a minimização de condições de desigualdade. Consideramos, também, que nos encontramos num contexto de políticas educativas globais, em que os países do Sul Global têm uma grande intensidade de influências globais, uma vez que são os mais pobres, com uma elevada dependência de ajuda externa em termos de financiamento (VERGER et al., 2012). Muitos desses países, graças à fragilidade dos respectivos Estados e à sua condição póscolonial, apresentam dependência econômica dos mercados transnacionais e de tendências sociopolíticas globais (CROSSLEY, 2001, p. 219; WILLIAMS, 2009). Nesse processo, emergem novos atores, que constroem, criam e implementam políticas educativas no âmbito das fronteiras nacionais. Entre eles, encontram-se atores privados transnacionais, organizações de investigação e empreendedores, os quais promovem as políticas educacionais que consideram adequadas (BALL, 2012; VERGER et al., 2012). Como consequência, tais países veem reduzida sua capacidade de "conduzir os seus sistemas educacionais" (BALL, 2012, p. 138).

Não obstante, não podemos descurar que, ao longo do tempo, a educação é um campo de disputas e de uma dominação epistemológica, que ocorre a diferentes ritmos históricos e sociais e não pode ter apenas uma leitura externa, pois os atores nacionais não são passivos - atuam, ao mesmo tempo, como criadores e interpretes (GEORGE; LEWIS, 2011; JANSEN, 2003; KASSAYE, 2013; LE GRANGE, 2013).

Tendo presente esse enquadramento, e que há organizações mais influentes (p. ex., Banco Mundial e Organização para a Cooperação e Desenvolvimento Econômico) do que outras, optamos por analisar os Planos Setoriais da Educação, ou documentos transitórios elaborados e submetidos pelos países africanos considerados frágeis à Parceria Global para a Educação (PGE) a fim de obter seu apoio financeiro, uma vez que esse é considerado o fundo internacional mais importante de apoio aos países do Sul Global. 
A PGE é uma parceria multi-stakeholders ${ }^{1}$, criada em 2002 pelo Banco Mundial com o nome Fast Track Initiative², da Educação para Todos. Em 2011, adquiriu uma nova roupagem, a fim de responder a várias críticas ao seu funcionamento, entre elas uma gestão pouco democrática, promoção de políticas educacionais motivadas por questões ideológicas (p. ex., preponderância de atores privados) entre outras (KNUTSSON; LINDBERG, 2019; 2020; MENASHY, 2016; 2017; 2019).

Atualmente, a PGE reúne setenta países do Sul Global e mais de vinte doadores. Considera-se a única parceria multilateral e o único fundo dedicados a que todas as crianças e todos os jovens do Sul Global tenham acesso à escola de modo a receberem educação de qualidade; bem como que potencia o apoio global e nacional no setor da educação, com foco nas crianças e nos jovens mais pobres e vulneráveis, canalizando mais de $60 \%$ do seu financiamento para os países frágeis ou afetados por conflito - 32 do total de países apoiados (GLOBAL..., 2019). O apoio da PGE implica o cumprimento de vários requisitos, entre eles a elaboração de um plano setorial da educação.

Apesar de haver a participação de toda essa tipologia de instituições, o Banco Mundial ou o UNICEF (United Nations Children's Fund) assumem, na maioria dos casos, um papel de destaque, particularmente nos países considerados frágeis ou afetados por conflito, onde as instituições governamentais e os serviços do Estado estão anêmicos.

A PGE foi selecionada para o presente estudo pelo papel preponderante que tem no apoio ao setor da educação nos países do Sul Global; na promoção de políticas educacionais motivadas por questões ideológicas (p. ex., preponderância de atores privados); por ter, no seu plano estratégico, apoio prioritário aos países frágeis e afetados por conflito; e por ser considerado que os Planos Setoriais de Educação sofrem forte influência dos doadores presentes nos países e dos consultores contratados para apoiar sua elaboração/ avaliação (MENASHY, 2017; 2019; MENASHY; DRYDEN-PETERSON, 2015).

A privatização da educação foi selecionada como leitmotiv desta análise, pois predomina no fundo em questão a promoção de políticas educacionais que dá preponderância aos atores privados, além do fato de que uma das inovações desse fundo é a participação do setor privado na sua administração. A investigação disponível também indica que a participação desses atores privados está relacionada com a promoção de suas agendas, orientadas pelo lucro, e tem como estratégia solidificar a relação com atores que tenham a capacidade para implementar suas iniciativas (KNUTSSON; LINDBERG, 2019; MENASHY, 2016; 2019). Outra questão é que a investigação sobre a PGE é escassa, em especial no Brasil e em países do Sul Global.

Foram analisados os Planos Setoriais da Educação, ou documentos transitórios mais recentes dos países africanos considerados frágeis até abril de 2020, disponíveis na página da PGE na Internet (https:// www.globalpartnership.org/where-we-work/partner-countries).

O diálogo aqui presente, entre os 24 países, emerge das seguintes proximidades e conexões:

- São do mesmo continente, africano, e são considerados frágeis por ter pelo menos uma das seguintes características: governo fraco, acompanhado de políticas ineficientes e instituições ainda não consolidadas, quer por falta de vontade de seus governantes, quer por incapacidade política ou econômica (BRANNELLY et al., 2009; DAVIES 2011; KIRK, 2007; BENGTSSON, 2011);

- Foram colonizados por países europeus;

- Recebem ou receberam recentemente apoio da PGE, tendo, para tanto, que cumprir vários requisitos, como elaborar um Plano Setorial da Educação, planos esses que sofrem forte influência dos doadores e/ou dos consultores contratados para apoiar a sua elaboração/avaliação.

Ainda que haja evidentes relações entre os países, há muitos elementos distintos entre eles, razão pela qual optamos por comparar um conjunto de elementos considerados estruturantes para o objeto analisado - elementos 
esses que emergiram da literatura: os referentes associados à privatização da educação. Nesse sentido, não há uma relação hierárquica entre os campos comparados (BRAY et al., 2015), mas um diálogo comparado a partir do estudo de como os 24 países materializam questões relacionadas com a privatização da educação nos seus Planos Setoriais da Educação, ou documentos transitórios que submeteram à PGE tendo em vista o seu apoio financeiro.

Importante destacar que, em consultas à plataforma Scientific Electronic Library Online (SciELO), à Web of Science e à Journal Storage (JSTOR), por meio de busca realizada pelo descritor "Global Partnership for Education" (Parceria Global para a Educação) no acervo disponível até abril 2020, apenas foram identificadas duas publicações que se debruçam sobre esse tema: uma sobre o apoio da PGE aos países frágeis e afetados por conflito (MENASHY; DRYDEN-PETERSON, 2015), outra sobre a PGE e os Países Africanos de Língua Oficial Portuguesa (SILVA, 2018).

O presente artigo encontra-se organizado em quatro partes. Na primeira, tecemos algumas considerações sobre as políticas educativas globais, como a PGE se enquadra nesse processo e as categorias de análise que emergem da literatura. Já na segunda, expomos a abordagem metodológica. Na terceira, apresentamos e discutimos os dados. Por fim, na quarta parte, intitulada “Considerações Finais", identificamos as principais conclusões.

\section{Políticas Educativas Globais, a Parceria Global para a Educação e os Países Frágeis e/ou Afetados por Conflito}

A ascensão da globalização esteve/está ativamente envolvida na remodelação de muitos sistemas educacionais de nível global, embora com múltiplas manifestações (KLEES et al., 2012; VERGER et al., 2016). As organizações internacionais e regionais têm papel fundamental em influenciar os sistemas educacionais ao redor do mundo (ADRIÃO, 2018; ANDERSON-LEVITT, 2008; CROSO; MAGALHÃES, 2016; RIZVI; LINGARD, 2010; SILVA et al., 2015; VERGER et al., 2012), dado que influenciam como certas políticas e/ou reformas educacionais são selecionadas, implementadas e avaliadas. Num primeiro momento, os efeitos econômicos tornam-se mais visíveis pela introdução de

[...] padrões de eficiência e qualidade, pela privatização de serviços e pela economização do conhecimento, aceitando-se que, a nível político, são cada vez mais convergentes os modos de regulação das políticas educacionais e que, a nível cultural, são transnacionalizados padrões comuns que resultam do reconhecimento de princípios quanto a modos de ser e de viver (PACHECO, 2009, p. 108).

Assistimos, em nível global, a discursos que consideram que o conceito de mercado educacional integre os princípios de escolha com os de liberdade para, dessa maneira, argumentar que, por exemplo, os operadores de escolas com fins lucrativos possam contribuir para objetivos nobres, como o acesso à educação dos mais pobres ou que padrões educacionais definidos internacionalmente originem educação de qualidade para todos (VERGER; STEINER-KHAMSI; LUBIENSKI, 2017). Esses discursos circulam pelas organizações, assim como, posteriormente, por ministérios e outros atores.

Nesse cenário, o espaço político se assemelha a um mercado de ideias, com a participação de diversos atores que atuam em três dimensões: gestão da educação, oferta educacional e currículo (ADRIÃO, 2018; MUNDY et al., 2016). Uma característica desse mercado de ideias é a ascensão do discurso e de práticas - em crescimento - sobre privatização da educação, ascensão essa que está intimamente relacionada com a existência de uma política educativa global (ROBERTSON, 2012; VERGER et al., 2012). Nesse mercado, há também grande capacidade material e ideológica para que agentes externos, principalmente no Sul Global, definam agendas e prioridades, pois esses países são os mais pobres e têm grande dependência de ajuda externa (VERGER et al., 2012). Contudo, os atores nacionais desses países do Sul Global não são passivos 
- atuam ao mesmo tempo como criadores e interpretes (GEORGE; LEWIS, 2012; KASSAYE, 2013; LE GRANGE, 2013), originando, por exemplo, o fato de que, apesar de a privatização da educação ter promotores poderosos e com bastante influência, tal fenômeno é contestado e encontra vários obstáculos e fontes de resistência, que provocam avanços e recuos (VERGER; STEINER-KHAMSI; LUBIENSKI, 2017).

O fenômeno da privatização da educação é multifacetado e contingente, uma vez que varia conforme o contexto onde ocorre, sendo caracterizado como processo de transformação social, não apenas de reforma. Há um consenso global, nos círculos acadêmicos e políticos, de que esse fenômeno está se expandindo internacionalmente. A privatização da educação é um fenômeno, de certa maneira, subpesquisado, no nível das políticas educacionais, na maioria dos contextos (BALL, 2007; ROBERTSON; DALE, 2013, p. 432; VERGER et al., 2016). Contudo, nos últimos anos, temos assistido a um aumento da literatura que aborda essa temática.

Os atores que participam, em nível global, da privatização da educação também são múltiplos, o que faz com que uma abordagem centrada apenas no Estado não seja suficiente para um olhar global sobre esse fenômeno. Isso porque os atores não estatais, como as organizações não governamentais e o setor privado, estão cada vez mais ativos nos vários domínios das políticas educacionais (VERGER et al., 2016), uma vez que fundações privadas e filantropos são agora membros de parcerias relacionadas com a educação no Sul Global (SRIVASTAVA; BAUR, 2016; SRIVASTAVA; OH, 2010).

De maneira global, a literatura internacional considera que podemos distinguir entre dois tipos principais de privatização: 1) privatização da educação pública, ou privatização “exógena”; 2) privatização na educação pública, ou privatização "endógena” (BALL; YOUDELL, 2007). Contudo, não devemos descurar que existem outras nuanças e formas de classificar este fenômeno.

No que se refere ao Sul Global, estamos assistindo à transição de uma estratégia de privatização de facto para uma de planejamento, dado que iniciativas de indivíduos ou comunidades - como as escolas de baixo custo, ou escolas comunitárias, que serviam, por exemplo, para suprir a ausência de uma oferta pública ou para colmatar a presença de uma oferta pública desadequada - estão sendo incorporadas nas estratégias nacionais e nas redes transnacionais (SRIVASTAVA, 2010). A privatização de facto é um processo aparentemente não relacionado com as políticas públicas, que ocorre por iniciativa dos pais, das comunidades e da sociedade civil, independentemente das políticas promovidas pelos Estados. Por outro lado, a privatização por planejamento ocorre quando as autoridades públicas promovem, de maneira proativa, a privatização da educação e implementam medidas explícitas para a promover, como, por exemplo, parcerias público-privadas e vouchers (VERGER et al., 2016).

Os países considerados frágeis e afetados por conflitos não estão imunes às reformas pró-mercado. Por vezes, a instabilidade vivida por esses países é usada como oportunidade para o avanço das políticas pró-mercado, uma vez que, nesses contextos, há resistência inferior à de outros países, em virtude do papel desempenhado por agentes externos, juntamente com a necessidade de uma resposta rápida que dificulta a existência de um debate transparente e abrangente (MENASHY; DRYDEN-PETERSON, 2015; MENASHY; ZAKHARIA, 2020; VERGER; FONTDEVILA; ZANCAJO, 2016; 2017; ZAKHARIA; MENASHY, 2020).

Entretanto, para efeito do tema a ser tratado neste artigo, compartilhamos do sentido atribuído aos processos de privatização da educação propostos por Belfield e Levin, os quais referem que a privatização da educação:

[...] é uma designação genérica de vários programas e políticas educativas que podem ser globalmente definidos como "a transferência de atividades, provisão e responsabilidades do governo/instituições e organizações públicas para indivíduos e organizações privadas”. Muitas vezes a privatização é vista como uma "liberalização" - quando os agentes são libertados das regulações governamentais - e uma "mercantilização" - quando são criados novos mercados que proporcionam alternativas aos serviços do governo ou aos sistemas de distribuição estatal (BELFIELD e LEVIN, 2004, p. 16). 
A PGE é uma parceria multi-stakeholders criada em 2002, em parte para possibilitar o aumento da colaboração entre o setor público e o privado (MENASHY, 2019). O modelo de parceria associado à PGE é o da globalização econômica neoliberal, que tem o potencial de ampliar as hierarquias de poder e comprometer a educação como bem público e direito humano, excluindo, além disso, a existência de outras mundividências, que permitem olhares diferentes sobre os mesmos fenômenos (ANDREOTTI, 2014; KLEES; QARGHA, 2014; MENASHY, 2019; ROBERTSON et al., 2012; SANTOS, 2010).

Nos últimos anos, as parcerias público-privadas têm predominado nas discussões, graças à crença da vantagem comparativa do setor privado em relação ao público e de que estamos num mundo de parcerias, mas com uma "vingança. Todo mundo diz que é parceiro de todo mundo" (KLEES; QARGHA, 2014, p. 228).

O Banco Mundial é a entidade que alberga a PGE em sua sede em Washington, nos Estados Unidos (GLOBAL..., 2019). A PGE é considerada um fundo vertical, uma vez que o financiamento que canaliza para os países é destinado apenas a um setor, nesse caso da educação. É também uma parceria públicoprivada, na medida em que inclui, na sua estrutura, governos do Norte Global - considerados doadores de ajuda ao desenvolvimento -, países do Sul Global - considerados receptores de ajuda ao desenvolvimento -, agências multilaterais, sociedade civil, fundações privadas e empresas, em que todos atuam como parceiros (KNUTSSON; LINDBERG, 2019; MENASHY, 2016; 2019; MENASHY; DRYDEN-PETERSON, 2015).

Todavia, na PGE, os atores do Norte Global detêm maior influência, sendo a voz dominante na tomada de decisões, principalmente porque são doadores. Dessa maneira, na PGE, predomina o poder estrutural que cria uma hierarquia e dá preponderância a certos atores em detrimento de outros mediante sua posição numa hierarquia, influenciando, assim, a participação e a capacidade de influência dos vários participantes (MENASHY, 2018; 2019).

Em nível internacional, os fundos com as características da PGE provocaram grande mudança nas relações internacionais, uma vez que promovem uma forma de governança que não se centra no Estado e demonstram a crescente autoridade dos atores privados na definição de políticas de nível global, dado que o setor privado não está apenas presente nesses fóruns, mas é parceiro de pleno direito (MENASHY, 2016; 2019; MENASHY; DRYDEN-PETERSON, 2015).

Global e nacionalmente, os atores privados têm legitimidade na PGE, com origem em fatores discursivos e crenças associadas às características desses atores, não na sua contribuição financeira e na capacidade de governança e/ou promoção de inovações. As motivações para esses atores privados participarem dessas parcerias está mais relacionada com a promoção das suas agendas, orientadas pelo lucro, bem como com a estratégia de solidificar a relação com atores que tenham a capacidade de implementar suas iniciativas (KNUTSSON; LINDBERG, 2019; MENASHY, 2016; 2019). Esses processos permitem que líderes empresariais assumam cada vez mais o papel de especialistas em políticas educacionais globais, participando mesmo das decisões relacionadas com os países frágeis e afetados por conflito, habitando esses espaços e envolvendo-se na formulação de políticas, por serem considerados detentores de competências como criatividade, eficiência, inovação e capacidades financeiras ilimitadas (MENASHY, 2018; 2019; MENASHY; DRYDEN-PETERSON, 2015).

Esses aspectos, como apontam os estudos de Knutsson e Lindberg (2019; 2020) e de Menashy (2016; 2019), geram desconfiança nas organizações da sociedade civil, principalmente quando estamos assistindo a um aumento de iniciativas privadas de educação de baixo custo nos países do Sul Global. Na PGE, o Banco Mundial assume preponderância como organização responsável pelo financiamento (Grant Agent) e o UNICEF, como agência de coordenação em nível nacional, predominando o inglês como língua de trabalho - a maioria dos documentos disponíveis está em inglês e francês -, o que reforça a posição de poder do Norte Global (MENASHY, 2017; 2018; 2019).

A PGE assume uma arquitetura de governança ambiciosa, que tem muitas características pós-políticas; ou seja, tenta despolitizar seu trabalho usando a ciência, as evidências científicas e as boas práticas para, assim, anular 
as questões políticas e passá-las para atores externos, supostamente neutros, dessa maneira fabricando consensos e tornando possível esse tipo de governança global (KNUTSSON; LINDBERG, 2020). Essas evidências científicas e boas práticas promovidas por várias organizações internacionais têm mais a ver com os desejos de influência das agências e com a receptividade local baseada em aspirações políticas do que com certezas de transferibilidade e evidências científicas da sua eficácia (SCHWEISFURTH; ELLIOTT, 2019).

Embora a PGE se apresente como parceria orientada por consenso e coerência, não deixa de ser um projeto hegemônico que não consegue, em vários temas (p. ex., apoio à escola de baixo custo, justiça fiscal global), ser coerente e promover o consenso (KNUTSSON; LINDBERG, 2019). Como acontece na maioria das parcerias, a PGE é uma parceria com desequilíbrios, prevalecendo os de poder, em que predominam iniciativas lideradas pelos países do Norte Global (KNUTSSON; LINDBERG, 2020; MENASHY, 2019).

Os Planos Setoriais da Educação, para ser considerados robustos pela PGE, devem ter as seguintes sete características (UNESCO, 2015):

- Apresentar uma visão geral que orienta todo o plano;

- Identificar as estratégias para alcançar a visão geral definida, que inclui as capacidades humanas, técnicas e financeiras necessárias à sua implementação;

- Ser holístico, incluindo todos os níveis de ensino;

- Ser baseado em evidências;

- Ser alcançável;

- Ser sensível à análise das vulnerabilidades do país, que inclui catástrofes e crises econômicas;

- Ter em consideração as disparidades internas de cada país.

Importa ainda referir, para efeito do tema tratado, o que se entende por Estado frágil/país frágil. Apesar de ser um conceito amplamente utilizado, principalmente pelos projetos de desenvolvimento internacional, é contestado, em especial pelos países etiquetados como tal - levando algumas agências a utilizarem o termo Estado resiliente, sem, contudo, alterar os pressupostos inerentes ao conceito, que incluem, entre outras, as seguintes características: governo anêmico, acompanhado de políticas ineficientes e instituições ainda não consolidadas, quer por falta de vontade de seus governantes, quer por desazo político ou debilidades econômicas (BENGTSSON, 2011; DAVIES, 2011; KIRK, 2007). Embora não exista definição consensual do que constitui um Estado/país frágil, bem como do que significa "frágil", parece haver certo consenso de que isso não se limita às áreas afetadas por conflito (DAVIES, 2011; OCDE, 2006). De acordo com Davies (2011), podemos identificar sete características como as mais comuns, que devemos levar em consideração quando abordamos as questões de fragilidade:

- Déficits de governança;

- Incapacidade de manter a segurança;

- Incapacidade de garantir necessidades essenciais;

- Polarização espacial de identidades;

- Fluxos de ajuda não governáveis;

- Tomada de decisão opaca por uma pequena elite;

- Erosão da confiança das pessoas no Estado.

Essas características parecem ser mais úteis na análise dos países do que a aplicação do termo "Estado frágil”/"país frágil”, pois focam a atenção em dimensões específicas de fragilidade sob contextos complexos, caracterizados pela mudança rápida e constante. Não obstante, apesar de considerarmos que o termo mais adequado seria "fragilidade", em detrimento de "Estado frágil”/"país frágil”, por ter uma conotação 
negativa e tratar os países como uma entidade homogénea, ao longo do artigo usaremos o termo "países frágeis", por ser essa a designação utilizada pela PGE.

\section{Metodologia}

O presente artigo tem por base a análise documental (documentos primários), sendo uma forma de investigação aplicável a todos os textos políticos e que não exige muitos recursos materiais. Foi utilizado esse tipo de análise por ser considerado técnica não interferente nos estudos de ciências sociais (LEE, 2003).

Os documentos utilizados podem ser classificados como textos políticos (OZGA, 2000) e caracterizados como dados preexistentes. Realizou-se uma utilização textual dos documentos em questão (QUIVY; CAMPENHOUDT, 2005). A análise centra-se nos Planos Setoriais da Educação, ou documentos transitórios submetidos à PGE quando da solicitação de apoio financeiro ao fundo pelos governos dos seguintes 24 países: Burundi; Camarões; Chade; Comores; Costa do Marfim; Eritreia; Gâmbia; Guiné-Bissau; Libéria; Mali; Moçambique; Níger; Nigéria; Quênia; República Centro-Africana; República Democrática do Congo; República do Congo; Ruanda; Somália; Sudão; Sudão do Sul; Togo; Uganda; e Zimbábue.

Partiu-se de uma análise categorial do conteúdo, baseada num sistema pré-definido, seguindo, assim, procedimento fechado em virtude das categorias emergirem do quadro teórico (BARDIN, 2007; ESTEVES, 2006) - neste caso, as componentes associadas à privatização da educação, identificadas por Silva, Santos e Pacheco (2015) e por Silva (2018).

Na Tabela 1, estão representados os cinco referentes associados à privatização da educação, que emergem da literatura e foram usados na análise dos documentos.

Tabela 1. Categoria e referentes

\begin{tabular}{|c|c|}
\hline Categoria & Referentes \\
\hline \multirow{5}{*}{ Privatização da educação } & 1 - Valorização da iniciativa privada \\
\hline & 2 - Uso do setor privado encorajado \\
\hline & 3 - Direito de escolha \\
\hline & 4 - Evocação da educação como serviço público de gestão privada \\
\hline & 5 - Diminuição da interferência do Estado \\
\hline
\end{tabular}

Fonte: Adaptado de Santos e Pacheco (2015) e Silva (2018).

Na Tabela 2, podemos observar: a(s) agência(as) que, em nível nacional, coordenam o financiamento da PGE; o nome do documento analisado; e língua em que foi redigido o Plano Setorial de Educação. Os 24 documentos analisados estão escritos em três línguas diferentes. Com exceção da Guiné-Bissau e da Somália, foram elaborados numa das línguas e/ou na língua oficial de cada país. Dessa maneira, contabilizamos onze documentos em inglês, doze em francês e um em português. Em relação à agência de coordenação de nível nacional, os dados indicam que predomina o UNICEF, seguido pela Agência dos Estados Unidos para o Desenvolvimento Internacional (USAID; do inglês, United States Agency for the International Development) e o Departamento de Desenvolvimento Internacional do Reino Unido (DFID; do inglês, Department for International Development). Isso corrobora a constatação de Menashy (2017) de que o UNICEF normalmente coordena, em nível nacional, os processos relacionados com a PGE. 
Tabela 2. Países, agência de coordenação e documentos analisados.

\begin{tabular}{|c|c|c|c|}
\hline & Agência de coordenação & Documento analisado & Idioma \\
\hline Burundi & UNICEF & $\begin{array}{l}\text { Plan Transitoire de l'Éducation au Burundi, } \\
\text { 2018-2020 }\end{array}$ & Francês \\
\hline Camarões & Unesco/UNICEF & $\begin{array}{c}\text { Document de Stratégie du Secteur de l'Education } \\
\text { et de la Formation }(2013-2020)\end{array}$ & Francês \\
\hline Chade & União Europeia & $\begin{array}{c}\text { Projet de Renforcement de l'Éducation et de } \\
\text { l'Alphabétisation au Tchad (PREAT) }\end{array}$ & Francês \\
\hline Comores & $\begin{array}{c}\text { Cooperação Suíça/Banco } \\
\text { Mundial/Ministério da Educação }\end{array}$ & $\begin{array}{l}\text { Plan de Transition du Secteur de l'Éducation, } \\
\text { 2017-2020. Comores }\end{array}$ & Francês \\
\hline $\begin{array}{l}\text { Costa do } \\
\text { Marfim }\end{array}$ & $\begin{array}{c}\text { Embaixada de França/Ministério } \\
\text { da Educação de França }\end{array}$ & Plan Sectoriel Education/Formation, 2016-2025 & Francês \\
\hline Eritreia & UNICEF & Eritrea Education Sector Plan & Inglês \\
\hline Gâmbia & UNICEF & Education Sector Strategic Plan, 2016-2030 & Inglês \\
\hline Guiné-Bissau & UNICEF & $\begin{array}{c}\text { Programme Sectoriel de l'Education de la Guinée } \\
\text { Bissau (2017-2025) }\end{array}$ & Francês \\
\hline Libéria & UNICEF & Getting to Best Education Sector Plan, 2017-2021 & Inglês \\
\hline Mali & UNICEF & $\begin{array}{c}\text { Programme Interimaire de Relance du Secteur } \\
\text { de l'Education et de la Formation Professionnelle } \\
\text { Duree: } 2 \text { Ans }(2015-2016)\end{array}$ & Francês \\
\hline Moçambique & UNICEF & A escola é nossa! - Plano Operacional, 2015-2018 & Português \\
\hline Níger & UNICEF & $\begin{array}{l}\text { Programme Sectoriel de l'Education et de la } \\
\text { Formation (2014-2024) - Document de stratégie }\end{array}$ & Francês \\
\hline Nigéria & USAID & $\begin{array}{l}\text { Federal Republic of Nigeria Appraisal of Education } \\
\text { Sector Plans of Five States of the North West Region }\end{array}$ & Inglês \\
\hline Quênia & UNICEF & $\begin{array}{c}\text { National Education Sector Plan Volume One: } \\
\text { Basic Education Programme Rationale and } \\
\text { Approach 2013/2014-2017/2018 }\end{array}$ & Inglês \\
\hline $\begin{array}{c}\text { República } \\
\text { Centro-Africana }\end{array}$ & Embaixada da Finlândia & $\begin{array}{c}\text { Programme d'Appui au Plan de Transition du } \\
\text { Système Éducatif Centrafricain }\end{array}$ & Francês \\
\hline $\begin{array}{l}\text { República } \\
\text { Democrática } \\
\text { do Congo } \\
\end{array}$ & União Europeia/UNICEF & $\begin{array}{l}\text { Stratégie Sectorielle de l'Éducation et de la } \\
\text { Formation, 2016-2025 }\end{array}$ & Francês \\
\hline $\begin{array}{l}\text { República do } \\
\text { Congo }\end{array}$ & DFID/USAID & $\begin{array}{c}\text { Strategie Sectorielle de l'Education, } \\
\text { 2015-2025 } \\
\end{array}$ & Francês \\
\hline Ruanda & UNICEF & Education Sector Strategic Plan, 2013/14-2017/18 & Inglês \\
\hline Somália & União Europeia/USAID & $\begin{array}{c}\text { Education Sector Program Improvement Grant, } \\
\text { 2018-2020 - Program Document }\end{array}$ & Inglês \\
\hline Sudão & USAID & $\begin{array}{l}\text { General Education Sector Strategic Plan } \\
-2018 / 19-2022 / 23\end{array}$ & Inglês \\
\hline Sudão do Sul & UNICEF & The General Education Strategic Plan, 2017-2022 & Inglês \\
\hline Togo & UNICEF & $\begin{array}{c}\text { Plan Sectoriel de l'Education PSE, 2014-2025 } \\
\text { - Amelioration de l'Acces, de l'Equite et de la } \\
\text { Qualite de l'Education au Togo }\end{array}$ & Francês \\
\hline Uganda & Embaixada da Bélgica/UNICEF & Education Sector Plan, 2004-2015 & Inglês \\
\hline Zimbábue & DFID & Education Sector Plan, 2016-2020 & Inglês \\
\hline
\end{tabular}


Os documentos não apresentam autores que possam ser associados à sua elaboração, com a exceção dos apresentados por Burundi, Camarões e República do Congo. Embora alguns documentos façam referência aos nomes de quem esteve envolvido na sua elaboração, tais pessoas nunca são identificadas como autoras, transparecendo que foi um processo com os princípios das declarações de Paris (OCDE, 2006) e Busan (OCDE, 2011) adotados pela PGE.

Essas declarações estão relacionadas com a ajuda pública ao desenvolvimento e à tentativa de a tornar mais eficaz. Para tanto, tais declarações promovem que os países receptores de ajuda pública ao desenvolvimento exerçam liderança efetiva sobre suas políticas e estratégias de desenvolvimento, bem como assegurem a coordenação dessas ações em seus países. Implicam também que os doadores baseiem todo o seu apoio nas estratégias nacionais de desenvolvimento, bem como que suas ações sejam mais harmonizadas, transparentes e coletivamente eficazes. Essas declarações incluem, ainda, a promoção de uma gestão e a tomada de decisões centrada nos resultados, para além de todos os intervenientes (países doadores e receptores da ajuda) serem responsáveis pelos resultados obtidos.

$\mathrm{Na}$ próxima seção, serão apresentados e analisados os dados, de acordo com as categorias e os referentes presentes na Tabela 1 .

\section{Análise e Discussão dos Dados}

Quando nos debruçamos sobre uma análise dos documentos de cada país, verificamos que seguem os pressupostos identificados pelas orientações da PGE para o que é considerado um robusto Plano Setorial da Educação (UNESCO, 2015). Dessa maneira, os documentos apresentam descrição global do estado da educação em cada país, com dados estatísticos sistematizados e uma descrição abrangente dos sistemas educacionais, do Pré-escolar ao Ensino Superior, incluindo os vários subsistemas (p. ex., alfabetização e educação de adultos). Os documentos identificam os desafios políticos e programáticos inerentes ao desenvolvimento contínuo da educação de cada país.

De acordo com as informações que pudemos recolher - e levando em consideração a situação de instabilidade política e as condições econômicas e sociais vividas nesses países -, as orientações anteriormente listadas e o apoio financeiro da PGE, bem como dos vários organismos que atuam no setor da educação em nível nacional, permitiram a realização de vários estudos, em cada um desses países, sobre, por exemplo: as crianças fora da escola; a formação dos professores; a recolha sistemática de dados estatísticos; e a sistematização da estatística escolar - todos processos que, de outra forma, não seriam realizados, não fosse a mobilização para a candidatura ao apoio financeiro da PGE. Não podemos descurar que esse processo de recolha de evidências faz parte da estratégia da PGE de tentar despolitizar as decisões tomadas em cada país (KNUTSSON; LINDBERG, 2020).

A Fig. 1 mostra a frequência de unidades de registo por país analisado com relação à privatização da educação. Já a Fig. 2 indica a frequência das unidades de registo em cada um dos referentes.

Da observação desses gráficos, considerando todos os países, podemos constatar que quatro deles se destacam pela maior frequência de unidades de registos - Guiné-Bissau, República Democrática do Congo, Somália e Sudão do Sul. Em relação aos vários referentes, destacam-se "2 - Uso do setor privado encorajado" e "4 - Evocação da educação como serviço público de gestão privada" com maior frequência de unidades de registo. No que concerne aos referentes com menos expressividade em relação à frequência de unidades de registo, temos o referente " 5 - Diminuição da interferência do Estado" - que não apresenta nenhuma unidade de registo - e o “3 - Direito de escolha” - com apenas uma unidade de registo, na Guiné-Bissau. 


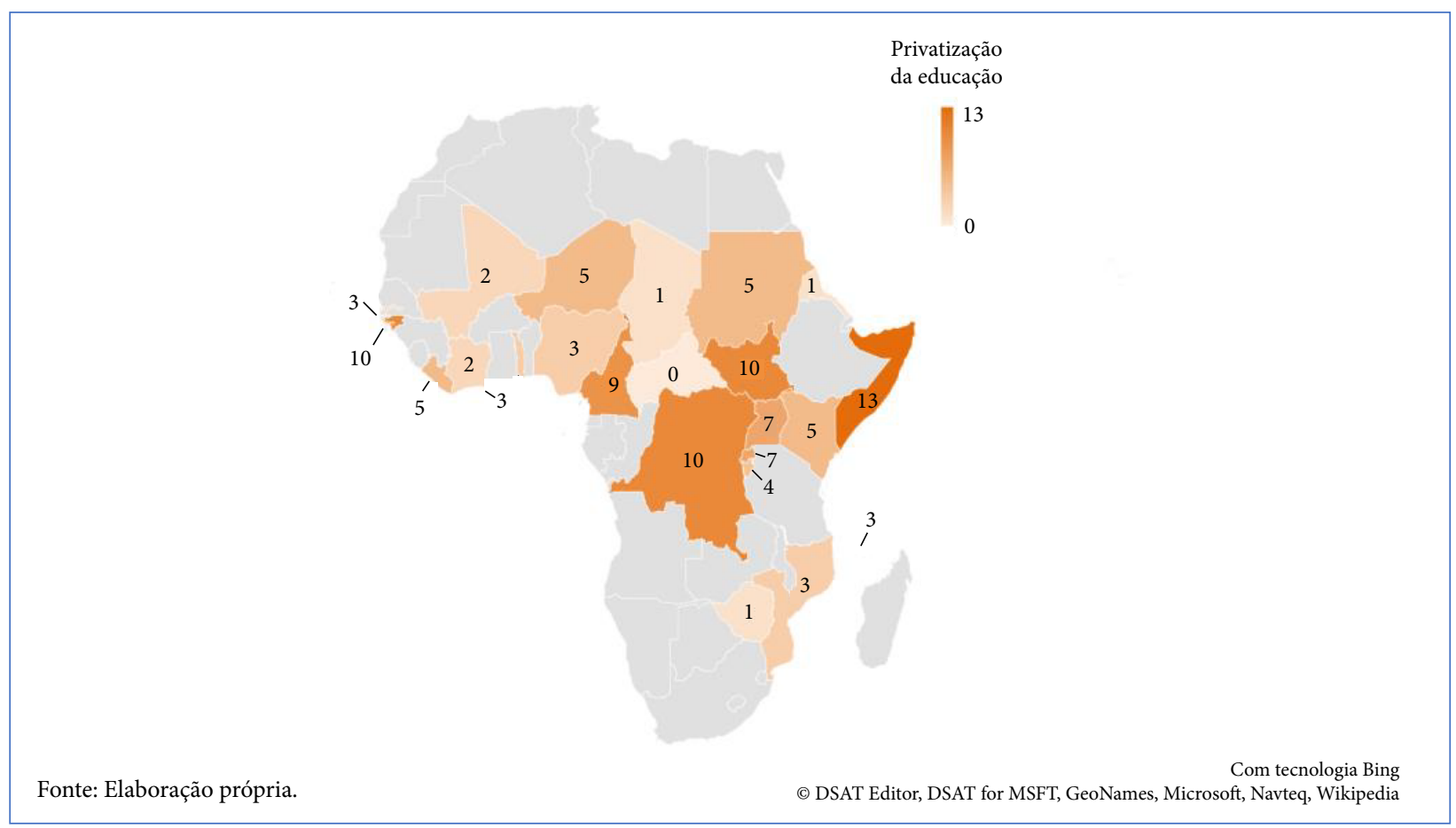

Figura 1. Localização geográfica e frequência da categoria de análise.

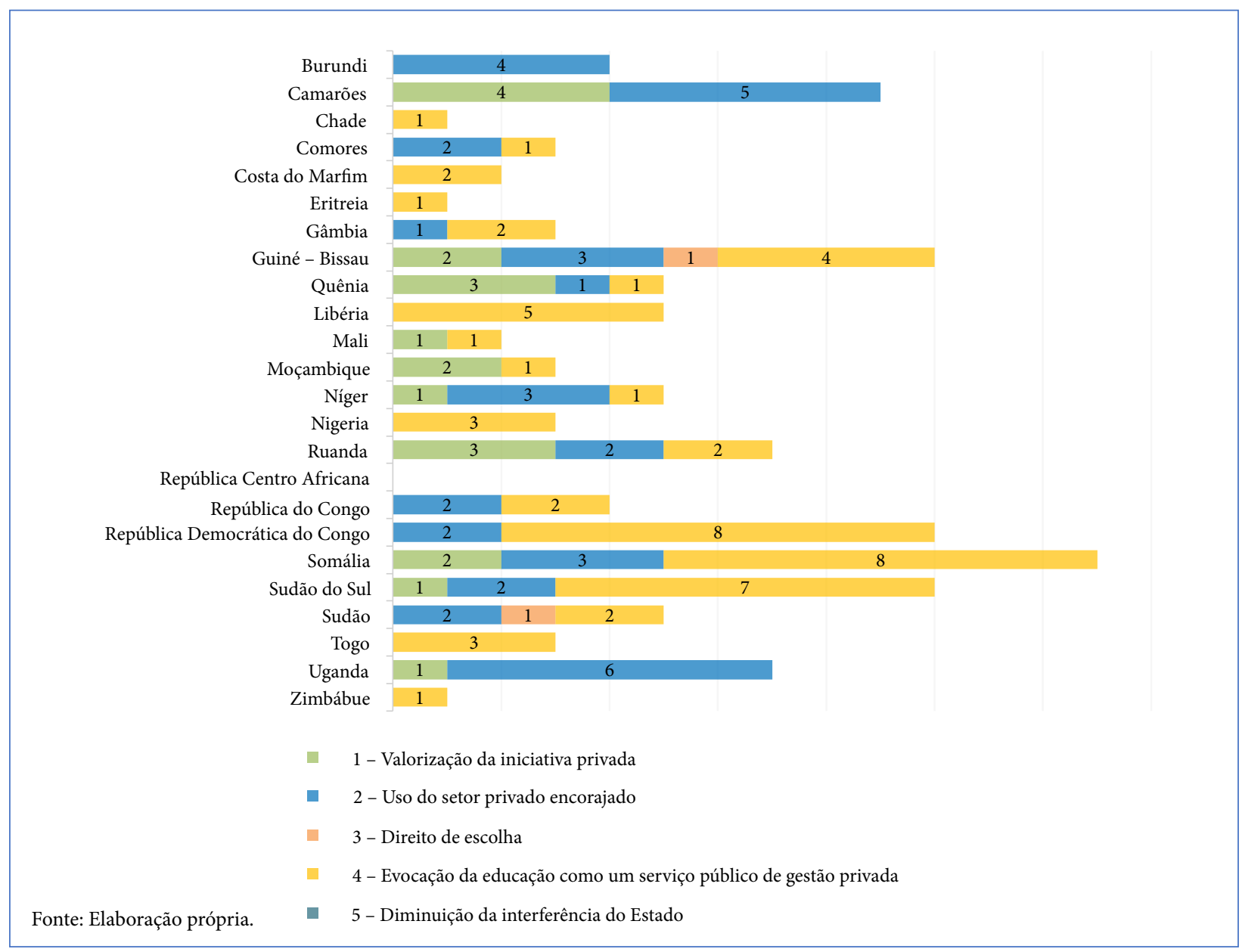

Figura 2. Frequência das unidades de registo por referente. 
Podemos também observar que a República Centro-Africana não apresenta unidades de registo em nenhum dos referentes e que Burundi, Chade, Costa do Marfim, Eritreia, Libéria, Nigéria, Togo e Zimbábue apenas têm unidades de registo em um dos referentes. A análise mais pormenorizada desses últimos permite constatar que, com exceção do Burundi - com unidades de registo no referente 2 -, esses países apresentam apenas unidades de registo no referente 4 , o qual tem maior frequência de unidades de registo na generalidade dos países.

A análise da Fig. 2 permite, ainda, constatar que Chade, Eritreia e Zimbabué apenas têm uma unidade de registo no referente 4 (Evocação da educação como serviço público de gestão privada), bem como que Burundi, Camarões e Uganda não apresentam nenhum registo nesse referente.

A razão que parece inerente ao fato de que o referente 4 (Evocação da educação como serviço público de gestão privada) tem maior frequência de unidades de registo é o predomínio, nos documentos, de uma perspectiva planejada da privatização da educação, que corresponde ao referido por Srivastava (2010). Contudo, não podemos esquecer que esse planejamento tem implícita a participação da comunidade/dos pais, bem como de microempreendedores, uma vez que os Estados não conseguem responder a toda a população graças às condições de fragilidade e/ou conflito e à realidade econômica e social. Logo, verifica-se uma tensão entre estratégias que foram desenvolvidas por indivíduos ou pela comunidade para suprir a ausência de uma oferta pública ou para colmatar a presença de uma oferta pública desadequada, as quais estão sendo incorporadas nas estratégias nacionais (SRIVASTAVA, 2010).

Quando nossa análise se debruça mais pormenorizadamente sobre os textos dos diferentes países, constatamos que cinco deles são atípicos no que concerne à tendência do que é considerado na literatura Costa do Marfim, República Centro-Africana, República do Congo, Somália e Quênia. No caso do Quénia, é referido que serão implementados vouchers no setor da educação (Education Voucher Scheme); contudo não é um sistema convencional de vouchers, pois destina-se apenas a apoiar os agregados familiares mais pobres e marginalizados para que possam asceder à educação pública. No caso de países como República do Congo e Somália, observamos que os documentos de cada país referem desejar diminuir a preponderância que o setor privado tem no setor da educação, a qual representa, nesses países, 67\% e 91\%, respetivamente. Não obstante, verificamos que, nos documentos dos países em questão, continuam a ser verificados a valorização do setor privado e o encorajamento do seu uso.

Em todos os documentos analisados, com exceção da Eritreia - que coloca no seu plano a justificação de algumas opções tendo por base a luta de libertação -, é reforçada a ideia de que as decisões são baseadas em evidências, na ciência, tentando dessa maneira, despolitizar os planos setoriais da educação e argumentando que são elaborados apenas com base nos dados de diagnóstico do sistema educacional e numa decisão técnica. Um exemplo dessa perspectiva é que temos países com número elevado de crianças fora da escola, como Guiné-Bissau ou República Democrática do Congo, que optam por incentivar o setor privado ou considerar a educação um serviço público, mas com gestão privada. Outro exemplo é o de Somália e Costa do Marfim, os quais colocam como meta diminuir o peso do setor privado, ou, ainda, o caso da Eritreia, a qual refere que a abrangência em nível nacional do setor público de educação é um fardo muito pesado para o Estado e uma das razões para o setor privado ser insignificante no país. Essa tentativa de despolitizar as decisões está alinhada com as características da PGE identificadas em nível global por Knutsson e Lindberg (2020).

Considerando que a situação política e que as condições econômicas e sociais desses países sejam conturbadas, bem como que haja níveis de pobreza elevados e deslocação de populações, encontramos estratégias como a utilização de professores voluntários ${ }^{3}$ - uma localização do global, dado que essa estratégia tem a particularidade de fundir dois objetivos, diferentes e potencialmente antagônicos: o direito à educação e a perspectiva neoliberal de mercado. Esse aspecto advém da tentativa de cumprir o compromisso de alcançar 
a educação para todos, um direito, e de cumprir esse direito usando contratação precária, a baixo custo, sem direitos trabalhistas dos professores, já que que não são oficialmente professores.

A coabitação entre esses dois princípios dá-se na medida em que o Estado não impede que comunidades, os pais e/ou as escolas contratem e paguem esses professores para suprir a falta de professores nas escolas, mas incluem nas estratégias dos países que integrem esses professores voluntários no sistema educacional, pois estão contribuindo para que as metas da educação para todos sejam alcançadas.

Essa estratégia está também inserida nas medidas de racionalização de custos do sistema educacional, originando a desprofissionalização dos professores. É a mesma estratégia usada por vários atores privados nas escolas de baixo custo para que os custos operacionais sejam diminuídos e as salas de aula sejam tratadas segundo o Tyler Rationale, que implica aceitação do currículo como plano (normativo), embora possa ser gerenciado pelos professores, se controlado pelo currículo nacional e pela avaliação padronizada (PACHECO, 2012). É também possível encontrar, na literatura, iniciativas promovidas por organizações internacionais que realizam estudos randomizados controlados, nos quais testam a performance dos professores voluntários e/ou precários, pagando-lhes salário abaixo do nível de pobreza do país (HOFFMANN, 2018). Países como Libéria, Níger, República Democrática do Congo, República do Congo, Sudão, Sudão do Sul e Togo têm previsto em seus planos o uso dos professores voluntários.

Quando analisamos o referente 1 (incentivo à iniciativa privada) de uma forma global, essa é predominante na educação infantil, no segundo segmento do Ensino Fundamental e no Ensino Médio. Nos documentos, é também claro que as estratégias dos países colocam ênfase no acesso à educação infantil, apostando em parcerias público-privadas ou na comunidade/nos pais. Essas estratégias conferem bastante importância a comunidades/pais e a iniciativas que não têm por fim último o lucro, já que levam em consideração os níveis de pobreza e dificuldade que as famílias enfrentam para colocar crianças e jovens na escola, bem como os números elevados de crianças fora dela. No caso do Sudão do Sul, por exemplo, é referido que se vai incentivar a iniciativa privada comunitária, que, depois de constituída e, de certa forma, consolidada, ficará sob responsabilidade do Estado, embora não apareçam definidos os moldes e a forma como essa transição entre privado e público se processará.

Nos países com população muçulmana elevada, como Chade, ilhas Comores, Costa do Marfim, Mali, Níger, Somália e Sudão, encontram-se referências à necessidade de o sistema educacional albergar ensino religioso que corresponda aos anseios da comunidade/dos pais, o que, em última análise, pode levar ao crescimento do ensino confessional privado, que, aliás, é já bastante elevado na Somália, ficando as escolas públicas para os mais marginalizados e para acolher as crianças fora da escola.

Quando analisamos em profundidade as unidades de registo do referente 4 (Evocação da educação como serviço público de gestão privada), notamos que o "gestor privado" se resume à comunidade/aos pais. Essa estratégia aparece enquadrada no pressuposto da participação/parceria entre escola e comunidade/pais na educação, conceito muito usado nos projetos de apoio ao desenvolvimento, com uma conotação positiva, pois é visto sob perspectiva emancipatória e democrática. Contudo, não podemos descurar que o modelo de parceria/participação predominante é o da globalização econômica neoliberal, que tem o potencial de ampliar as hierarquias de poder e comprometer a educação como bem público e direito humano. Esse aspecto deriva do facto de que a parceria/participação das comunidades implica seu envolvimento nas obras de reabilitação das escolas, no pagamento de incentivos aos professores, no pagamento de professores voluntários, entre outros. Essas estratégias também desresponsabilizam o Estado de realizar investimento na educação. Dessa maneira, tal estratégia junta uma agenda em que a educação é um bem público e um direito humano com uma em que é um bem privado sujeito à competição do mercado. 


\section{Considerações Finais}

O artigo buscou analisar as principais tendências que caracterizam o fenômeno da privatização da educação em 24 países africanos, partindo da análise documental dos Planos Setoriais da Educação, ou dos documentos transitórios elaborados e submetidos pelos países à PGE para obter seu apoio financeiro. Foi realizada análise documental baseada num sistema pré-definido (BARDIN, 2007; ESTEVES, 2006), dado que as categorias de análise emergem do quadro teórico.

Pôde-se constatar que, globalmente, os documentos dos 24 países seguem os pressupostos identificados pelas orientações da PGE para o que é considerado um Plano Setorial da Educação robusto, bem como que tais orientações e o apoio financeiro da PGE e dos vários organismos que atuam no setor da educação em nível nacional permitiram a realização vários estudos que, de outra maneira, não seriam realizados. Em todos os documentos analisados, com a exceção da Eritreia, que justifica algumas das opções do seu Plano Setorial da Educação tendo por base pressupostos inerentes à luta de libertação, os Planos Setoriais deixam claro que as decisões são baseadas em evidências científicas, tentando, assim, despolitizar as decisões. Esta perspectiva, portanto, está alinhada com as características da PGE identificadas em nível global por Knutsson e Lindberg (2020).

Os Planos Setoriais da Educação de Costa do Marfim, República Centro-Africana, República do Congo, Somália e Quênia são atípicos, uma vez que têm previstas medidas que não seguem as tendências verificadas na literatura no que concerne à privatização da educação (p. ex., redução do setor privado).

Podemos ainda concluir que, na maioria dos documentos, observa-se a articulação de dois objetivos diferentes e, em princípio, antagônicos - o direito à educação e perspectiva neoliberal de mercado -, uma vez que a pesquisa indica que, quando os Estados dependem da privatização para expandir o acesso à educação, essa abordagem pode entrar em conflito com a promoção da universalização do acesso, especialmente para as populações mais marginalizadas.

No que se refere à iniciativa privada, é predominante globalmente na educação infantil, no segundo segmento do Ensino Fundamental e no Ensino Médio. Nos documentos, é também claro que as estratégias dos países colocam ênfase no acesso à educação infantil, apostando em parcerias público-privadas ou na comunidade/nos pais, sendo mesmo referido que, depois de essas iniciativas comunitárias estarem, de certa forma, consolidadas, ficarão sob responsabilidade do Estado. Assim, os Planos Setorias da Educação deixam claro que as parcerias público-privadas ou comunidade/pais serão os principais responsáveis pelo acesso à educação infantil.

Dos cinco referentes utilizados na análise, os que têm mais unidades de registo são o 2 (uso do setor privado encorajado) e o 4 (evocação da educação como serviço público de gestão privada).

Como balanço final, podemos concluir que a República Centro-Africana não apresenta unidades de registo em nenhum dos referentes e que quatro países se destacam com frequência maior de unidades de registo - Guiné-Bissau; República Democrática do Congo; Somália e Sudão do Sul. Não obstante, países como Burundi, Chade, Costa do Marfim, Eritreia, Libéria, Nigéria, Togo e Zimbábue apresentam unidades de registo apenas no referente 4, com exceção do Burundi - com unidades de registo no referente 2 (uso do setor privado encorajado).

A prevalência do referente 4 (evocação da educação como serviço público de gestão privada) está associado ao fato de predominar nos documentos a privatização da educação planejada em detrimento da de facto. Contudo, não podemos descurar que esse planejamento tem implícita a participação da comunidade/ dos pais e de microempreendedores, uma vez que os Estados não conseguem responder a toda a população graças às condições de fragilidade e/ou conflito, bem como às condições econômicas e sociais. Logo, há tensão 
entre estratégias que foram desenvolvidas por indivíduos ou pela comunidade para ultrapassar a ausência de uma oferta pública ou para colmatar a presença de uma oferta pública desadequada, que estão sendo incorporadas nas estratégias nacionais (SRIVASTAVA, 2010).

Por fim, podemos concluir que gestão privada nos documentos diz respeito à comunidade/aos pais, estratégia que aparece enquadrada no pressuposto da participação/parceria entre escola e comunidade/pais na educação, um conceito muito usado nos projetos de apoio ao desenvolvimento, com uma conotação positiva, uma vez que é visto numa perspectiva emancipatória e democrática. Não obstante, não podemos descurar que o modelo de parceria/participação predominante é o da globalização econômica neoliberal, que tem o potencial de ampliar as hierarquias de poder e comprometer a educação como bem público e direito humano. Essa estratégia funde duas agendas: uma que perspectiva a educação como bem público e direito humano e outra como bem privado sujeito à competição do mercado.

A comparação entre os países mostra as tensões entre globalização e localização e as condições sob as quais o global é localizado (DALE; ROBERTSON, 2004; SANTOS, 2002), nesse caso, a gestão privada da educação, além de como se difunde a ideia de que as decisões de política educacional têm por base unicamente decisões técnicas, não políticas.

\section{Contribuições dos Autores}

Problematização e Conceitualização: Silva R e Oliveira J; Metodologia: Silva R; Análise: Silva R e Oliveira J; Redação: Silva R e Oliveira J.

\section{Notas}

1. Uma parceria multi-stakeholders é um fórum para colaboração, coordenação e tomada de decisões que reúne organizações com diferentes tipologias, mandatos e proveniências geográficas (Norte e Sul Globais), incluindo organizações multilaterais, governamentais, da sociedade civil, fundações e empresas privadas (MENASHY, 2019).

2. A Fast Track Initiative foi um fórum multilateral que pretendia harmonizar a ajuda pública ao desenvolvimento, fortalecer os planos nacionais de educação dos países do Sul Global para melhorar a eficácia da ajuda ao desenvolvimento, coordenar o apoio dos doadores e promover o financiamento necessário para alcançar a educação primária universal até 2015.

3. Os professores voluntários são membros da comunidade que, graças à ausência de professores qualificados, são integrados nas escolas como professores. A formação acadêmica é variável, podendo ir do $4^{\circ}$ ano de escolaridade até o Ensino Superior.

\section{Referências}

ADRIÃO, T. Dimensões e formas da privatização da educação no Brasil: Caracterização a partir de mapeamento de produções nacionais e internacionais. Currículo sem Fronteiras, v. 18, n. 1, p. 8-28, 2018.

ANDERSON-LEVITT, K. M. Globalization and Curriculum. In: CONNELLY, F. M.; HE, M. F.; PHILLION, J. (orgs.). The SAGE Handbook of Curriculum and Instruction. London: SAGE Publications, 2008, p. 349-368. 
ANDREOTTI, V. Educação para a cidadania global - Soft vs Critical. Sinergias - Diálogos Educativos para a Transformação Social, n. 1, p. 57-66, 2014.

BALL, S. J. Education plc: Understanding private sector participation in public sector education. London: Routledge, 2007.

BALL, S. J. Global Education Inc.: New policy networks and the neo-liberal imaginary. London: Routledge, 2012.

BALL, S. J.; YOUDELL, D. Hidden Privatisation in Public Education. In: EDUCATION INTERNATIONAL, $5^{\text {th }}$ WORLD CONGRESS, 2007, Brussels, Preliminary Report, July 2007.

BARDIN, L. Análise de conteúdo. 4. ed. Lisboa: Edições 70, 2007.

BELFIELD, C. R.; LEVIN, H. M. A privatização da educação: Causas e implicações. Lisboa: Edições ASA, 2004.

BENGTSSON, S. E. L. Fragile states, fragile concepts: A critical reflection on the terminology of fragility in the field of education in emergencies. In: PAULSON, J. (org.). Education, conflict and development. Oxford: Symposium Books, 2011, p. 33-58.

BRANNELLY, L.; NDARUHUTSE, S.; RIGAUD, C. Donors' Engagement: Supporting education in fragile and conflict-affected states. Paris: Unesco/ CfBT Education Trust, 2009

BRAY, M.; ADAMSON, B.; MASON, M. Pesquisa em educação comparada: Abordagens e métodos. Brasília: Liber Livro, 2015.

CROSO, C.; MAGALHÃES, G. M. Privatização da educação na América Latina e no Caribe: Tendências e riscos para os sistemas públicos de ensino. Educação \& Sociedade, Campinas, v. 37, n. 134, p. 17-33, jan.mar. 2016. https://doi.org/10.1590/ES0101-73302016157622

CROSSLEY, M. Cross-cultural issues, small states and research: Capacity building in Belize. International Journal of Educational Development, v. 21, n. 3, p. 217-229, 2001. https://doi.org/10.1016/S0738-0593 (00)00030-4

DALE, R.; ROBERTSON, S. Interview with Boaventura de Sousa Santos. Globalisation, Societies and Education, v. 2, n. 2, p. 147-160, 2004. https://doi.org/10.1080/14767720410001733629

DAVIES, L. Learning for state-building: Capacity development, education and fragility. Comparative Education, v. 47, n. 2, p. 157-180, 2011. https://doi.org/10.1080/03050068.2011.554085

ESTEVES, M. Análise de conteúdo. In: LIMA, J. A. D.; PACHECO, J. A. (orgs.). Fazer investigação. Contributos para a elaboração de dissertações e teses. Porto: Porto Editora, 2006, p. 105-125.

GEORGE, J.; LEWIS, T. Exploring the global/local boundary in education in developing countries: The case of the Caribbean. Compare: A Journal of Comparative and International Education, v. 41, n. 6, p. 721-734, 2012. https://doi.org/10.1080/03057925.2011.579712

GLOBAL PARTNERSHIP FOR EDUCATION. Factsheet - August 2019. Washington, D. C.: Global Partnership for Education. 2019.

HOFFMANN, N. When are experiments corrupt? Journal of Contemporary African Studies, v. 36, n. 4, p. 532-552, 2018. https://doi.org/10.1080/02589001.2019.1579893 
JANSEN, J. D. What education scholars write about curriculum in Namibia and Zimbabwe. In: PINAR, W. F. (org.). International Handbook of Curriculum Research. Mahwah: Lawrence Erlbaum Associates, 2003, p. 471-478.

KASSAYE, W. Curriculum development and research in Ethiopia. In: PINAR, W. F. (org.) International Handbook of Curriculum Research. London: Routledge, 2013, p. 161-182.

KIRK, J. Education and fragile states. Globalisation, Societies and Education, v. 5, n. 2, p. 181-200, 2007.

KLEES, S. J.; QARGHA, O. Equity in education: The case of UNICEF and the need for participative debate. Prospects, v. 44, n. 3, p. 321-333, 2014. https://doi.org/10.1007/s11125-014-9295-0

KLEES, S. J.; SAMOFF, J.; STROMQUIST, N. P. Conclusion. In: KLEES, S. J. et al. (orgs.). The World Bank and education: Critiques and alternatives. Rotterdam: Sense Publishers, 2012, p. 227-238.

KNUTSSON, B.; LINDBERG, J. On the absent ground of transnational partnerships in education: A postfoundational intervention. Globalisation, Societies and Education, v. 17, n. 4, p. 432-444, 2019. https://doi. org/10.1080/14767724.2019.1583090

KNUTSSON, B.; LINDBERG, J. Depoliticisation and dissensus in the global partnership for education: Rethinking the post-political condition. Journal of International Relations and Development, v. 23, n. 2, p. 436-461, 2020. https://doi.org/10.1057/s41268-018-0141-5

LE GRANGE, L. Curriculum Research in South Africa. In: PINAR, W. F. (org.). International Handbook of Curriculum Research. London: Routledge, 2013, p. 466-475.

LEE, R. Métodos não interferentes em pesquisa social. Lisboa: Gradiva, 2003.

LEVIN, H. Privatizing education. Can the marketplace deliver choice, efficiency, equity and social cohesion? Cambridge: Westview Press, 2001.

LUBIENSKI, C. Do quasi-markets foster innovation in education? A comparative perspective. Paris: OCDE, 2009.

MCCOWAN, T. Education as a human right. Principles for a universal entitlement to learning. London: Bloomsbury Academic, 2013.

MENASHY, F. Understanding the roles of non-state actors in global governance: Evidence from the Global Partnership for Education. Journal of Education Policy, v. 31, n. 1, p. 98-118, 2016. https://doi.org/10.108 0/02680939.2015.1093176

MENASHY, F. The limits of multistakeholder governance: The case of the Global Partnership for Education and Private Schooling. Comparative Education Review, v. 61, n. 2, p. 240-268, May 2017. https://doi. org/10.1086/690839

MENASHY, F. Multi-stakeholder aid to education: Power in the context of partnership. Globalisation, Societies and Education, 16, n. 1, p. 13-26, 2018. https://doi.org/10.1080/14767724.2017.1356702

MENASHY, F. International aid to education: Power dynamics in an era of partnership. New York: Teachers College Press, 2019. 
MENASHY, F; DRYDEN-PETERSON, S. The Global Partnership for Education's evolving support to fragile and conflict-affected states. International Journal of Educational Development, v. 44, p. 82-94, 2015. https:// doi.org/10.1016/j.ijedudev.2015.07.001

MENASHY, F.; ZAKHARIA, Z. Private engagement in refugee education and the promise of digital humanitarianism. Oxford Review of Education, v. 46, n. 3, p. 313-330, 2020. https://doi.org/10.1080/0305 4985.2019.1682536

MUNDY, K. et al. The Handbook of Global Education Policy. West Sussex: Wiley-Blackwell, 2016.

OCDE [ORGANISATION DE COOPÉRATION ET DE DÉVELOPPEMENT ÉCONOMIQUES]. Declaração de Paris sobre a Eficácia da Ajuda ao Desenvolvimento. Lisboa: Instituto Português de Apoio ao Desenvolvimento (IPAD), 2006.

OCDE [ORGANISATION DE COOPÉRATION ET DE DÉVELOPPEMENT ÉCONOMIQUES]. Parceria de Busan para uma cooperação eficaz para o desenvolvimento. In: $4^{\circ}$ FÓRUM DE ALTO NÍVEL SOBRE A EFICÁCIA DA AJUDA, 2011, Busan, República da Coreia, 29 nov.-1º dez. 2011. Disponível em: http:// www.oecd.org/development/effectiveness/OUTCOME\%20DOCUMENT\%20-\%20FINAL\%20(POR).pdf. Acesso em: $1^{\circ}$ abr. 2020.

OCDE [ORGANISATION DE COOPÉRATION ET DE DÉVELOPPEMENT ÉCONOMIQUES]. The challenge of capacity development: Working towards good practice. Paris: OCDE, 2006.

OZGA, J. Investigação sobre políticas educacionais: Terreno de contestação. Porto: Porto Editora, 2000.

PACHECO, J. A. Processos e práticas de educação e formação: Para uma análise da realidade portuguesa em contextos de globalização. Revista Portuguesa de Educação, v. 22, n. 1, p. 105-143, 2009. https://doi. org/10.21814/rpe.13955

PACHECO, J. A. Curriculum studies: What is the field today? Journal of the American Association for the Advancement of Curriculum Studies, v. 8, p. 1-18, 2012. https://doi.org/10.14288/jaaacs.v8i0.187713

QUIVY, R.; CAMPENHOUDT, L. V. Manual de investigação em Ciências Sociais. 4. ed. Lisboa: Gradiva, 2005.

RIZVI, F. Privatization in education: Trends and consequences. Paris: Unesco, 2016.

RIZVI, F.; LINGARD, B. Globalizing education policy. London: Routledge, 2010.

ROBERTSON, S. L. Researching global education policy: Angles in/on/out... In: VERGER, A.; NOVELLI, M.; LTINYELKEN, H. K. (orgs.). Global education policy and international development: New agendas, issues and policies. London: Bloomsbury Academic, 2012, p. 33-51.

ROBERTSON, S. L.; DALE, R. The social justice implications of privatisation in education governance frameworks: A relational account. Oxford Review of Education, v. 39, n. 4, p. 426-445, 2013. https://doi.org /10.1080/03054985.2013.820465

ROBERTSON, S. L. et al. Public private partnerships in education: New actors and modes of governance in a globalizing world. Cheltenham: Edward Elgar Publishing, 2012.

SANTOS, B. S. Globalização: Fatalidade ou utopia. Porto: Afrontamento, 2002. 
SANTOS, B. S. Para além do pensamento abissal: Das linhas globais a uma ecologia de saberes. In: SANTOS, B. S.; MENESES, M. P. (orgs.). Epistemologias do Sul. Coimbra: Edições Almedina, 2010, p. 23-71.

SCHWEISFURTH, M.; ELLIOTT, J. When 'best practice' meets the pedagogical nexus: Recontextualisation, reframing and resilience. Comparative Education, v. 55, n. 1, p. 1-8, 2019. https://doi.org/10.1080/030500 68.2018.1544801

SILVA, R. O papel da Parceria Global para a Educação na promoção dos referentes da globalização nos Planos Setoriais da Educação dos PALOP. Revista on line de Política e Gestão Educacional, Araraquara, v. 22, n. esp. 3, p. 1258-1275, dez. 2018. https://doi.org/10.22633/rpge.v22iesp3.12010

SILVA, R.; SANTOS, J. G.; PACHECO, J. A. Crossed looks: Globalisations and curriculum in Guinea-Bissau. Compare: A Journal of Comparative and International Education, v. 45, n. 6, p. 978-999, 2015. https://doi. org/10.1080/03057925.2015.1013018

SRIVASTAVA, P. Privatization and education for all: Unravelling the mobilizing frames. Development, v. 53, n. 4, p. 522-528, 2010. https://doi.org/10.1057/dev.2010.88

SRIVASTAVA, P.; BAUR, L. New global philanthropy and philanthropic governance in education in a post-2015 world. In: MUNDY, K. et al (orgs.). The Handbook of Global Education Policy. West Sussex: Wiley-Blackwell, 2016, p. 433-448.

SRIVASTAVA, P.; OH, S.-A. Private foundations, philanthropy, and partnership in education and development: Mapping the terrain. International Journal of Educational Development, v. 30, n. 5, p. 460-471, 2010. https://doi.org/10.1016/j.ijedudev.2010.04.002

UNESCO [UNITED NATIONS EDUCATIONAL, SCIENTIFIC AND CULTURAL ORGANISATION]. Guidelines for Education Sector Plan Preparation. Paris: Unesco, 2015.

VERGER, A.; FONTDEVILA, C.; ZANCAJO, A. The privatization of education: A political economy of global education reform. New York: Teachers College Press, 2016.

VERGER, A.; FONTDEVILA, C.; ZANCAJO, A. Multiple paths towards education privatization in a globalizing world: A cultural political economy review. Journal of Education Policy, v. 32, n. 6, p. 757-787, 2017. https://doi.org/10.1080/02680939.2017.1318453

VERGER, A.; NOVELLI, M.; ALTINYELKEN, H. K. Global education policy and international development: An introductory framework. In: VERGER, A.; NOVELLI, M.; ALTINYELKEN, H. K. (orgs.). Global education policy and international development: New agendas, issues and policies. London: Bloomsbury Academic, 2012, p. 3-31.

VERGER, A.; STEINER-KHAMSI, G.; LUBIENSKI, C. The emerging global education industry: Analysing market-making in education through market sociology. Globalisation, Societies and Education, v. 15, n. 3, p. 325-340, 2017. https://doi.org/10.1080/14767724.2017.1330141

WILLIAMS, L. Globalisation of education policy: Its effects on developing countries. In: ZAJDA, J.; RUST, V. (orgs.). Globalisation, policy and comparative research. Discourses of globalization. Netherlands: Springer, 2009, p. 77-92.

ZAKHARIA, Z.; MENASHY, F. The emerging role of corporate actors as policymakers in education in emergencies: Evidence from the Syria refugee crisis. Journal on Education in Emergencies, v. 5, n. 2, p. 40-70, 2020. https://doi.org/10.33682/pcbg-2fu2 


\section{Sobre os Autores}

RUI DA Silva é investigador integrado e Presidente da direção do Centro de Estudos Africanos da Universidade do Porto (CEAUP). Mestre e doutor em Ciências da Educação com especialidade em Desenvolvimento Curricular pela Universidade do Minho. Desenvolveu trabalho como investigador, consultor e especialista de educação em Angola, Cabo Verde, Guiné-Bissau, Sudão do Sul e Timor-Leste.

Joana Oliveira é professora adjunta da Escola Superior de Educação do Instituto Politécnico de Viana do Castelo e pesquisadora do Centro de Estudos Africanos da Universidade do Porto (CEAUP). Doutora em Ciências pela Universidade do Minho. Pós-doutora em Educação, especializada em Educação Ambiental e para a Sustentabilidade.

Recebido: 25 maio 2020

Aceito: 06 jul 2020 